\title{
COMPARISON OF MANUAL AND AUTOMATED PRETREATMENT METHODS FOR AMS RADIOCARBON DATING OF PLANT FOSSILS
}

\author{
$L E E-A N N$ BRADLEY
}

U. S. Geological Survey, Branch of Earthquake and Landslide Hazards, MS 966, Denver, Colorado 80225 USA

and

THOMAS W. STAFFORD, JR.

INSTAAR, The University of Colorado, Boulder, Colorado 80303 USA, and U.S. Geological Survey, Branch of Isotope Geology, MS 963, Denver, Colorado 80225 USA

\begin{abstract}
A new automated pretreatment system for the preparation of materials submitted for accelerator mass spectrometry (AMS) analysis is less time-consuming and results in a higher sample yield. The new procedure was tested using two groups of plant fossils: one group was pretreated using the traditional method, and the second, using the automated pretreatment apparatus. We compared the time it took to complete the procedure and the amount of sample material remaining. The automated pretreatment apparatus proved to be more than three times faster and, in most cases, produced a higher yield. We also observed a darker discoloration of the $\mathrm{KOH}$ solutions, indicating that the automated system is more thorough in removing humates from the specimen compared to the manual method.
\end{abstract}

\section{INTRODUCTION}

Chemical pretreatment of routine samples for AMS ${ }^{14} \mathrm{C}$ analysis is labor intensive, requiring as much as one-third of the time required for a complete sample analysis. Standard manual pretreatment methods (Gagnon and Jones 1993) are slow because a technician can process only 1 or 2 samples at a time. These methods also commonly result in a large percentage of sample loss. To speed pretreatment time and reduce sample loss, we designed and constructed an automated system controlled by a personal computer (Fig. 1). The system runs multiple samples simultaneously and yields a higher percentage of sample material. Here we compare pretreatment results of 11 samples using standard manual methods and our automated system. On average, the automated system reduced pretreatment time by $70 \%$ and sample loss by $4 \%$.

\section{METHODS}

Eleven plant fossils of different ages were selected to demonstrate the effects of manual and automated pretreatment methods on the types of materials commonly submitted for AMS analysis (Table 1). All specimens were cleaned of foreign matter, and split into two samples weighing 0.01$0.10 \mathrm{~g}$. One sample was pretreated using the manual method (denoted by a suffix $\mathrm{M}$ on the sample number), and the other sample was pretreated using the automated system (suffix $\mathrm{A}$ ). The samples were weighed before and after the pretreatment procedures to determine the amount of sample loss. Pretreatment times do not include drying time. All samples were processed through the same sequence of reagents (Table 2). Deionized water and distilled $\mathrm{HCl}$ were used for reagent mixing and to decrease contamination; all glassware was heated to $550^{\circ} \mathrm{C}$ for $1 \mathrm{~h}$.

\section{Automated Pretreatment Method}

Each sample was placed in a vertical borosilicate glass column (10 mm ID $\times 100 \mathrm{~mm}$ long) with a Teflon filter end-cap fixed to each end (Fig. 2). The filter end-caps were fitted with $25-\mu$ polyethylene disposable frits that were replaced with each sample change. Teflon tubing leading from pressurized reagent containers were attached to the top filter end-cap to allow reagents to flow through 


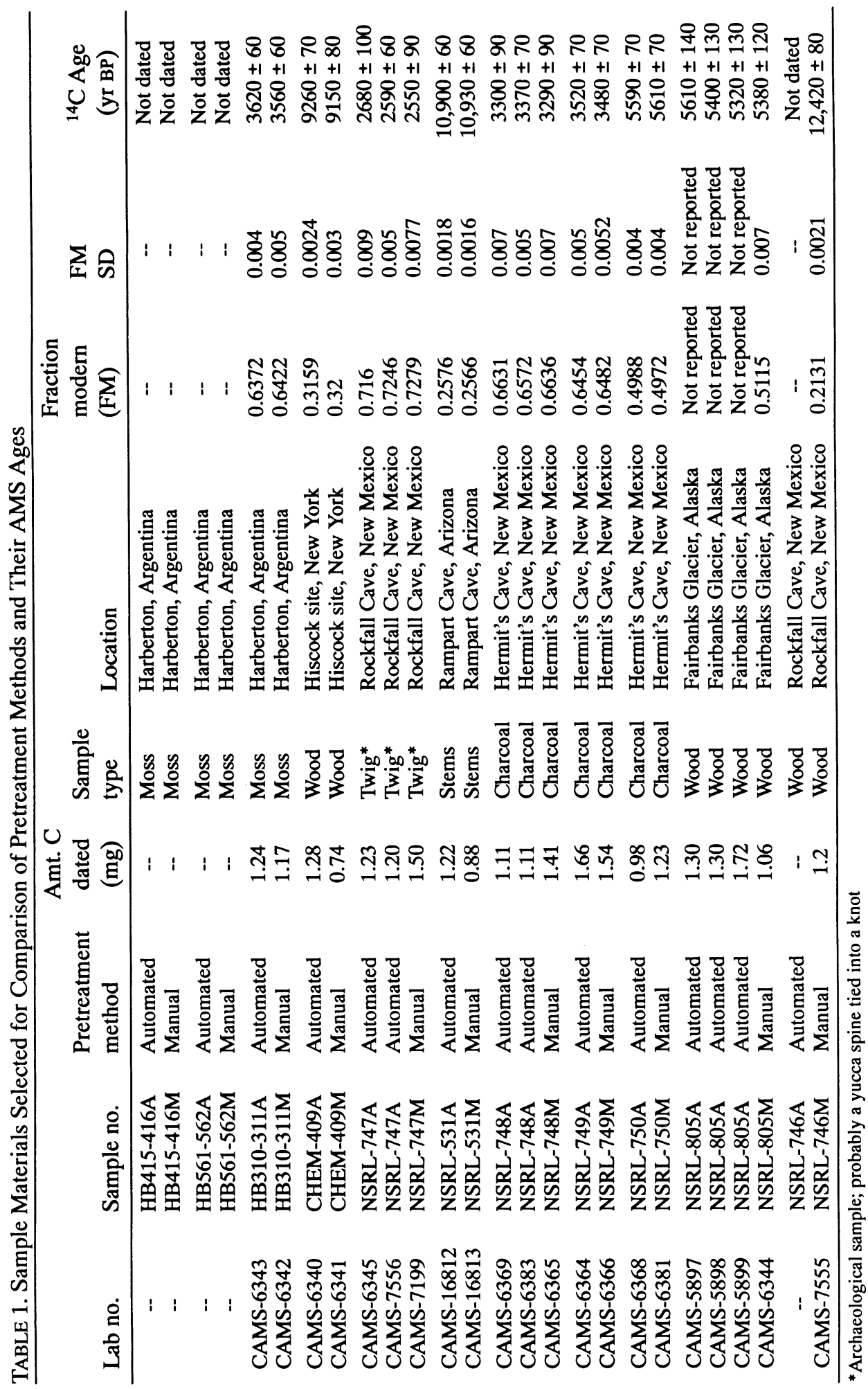




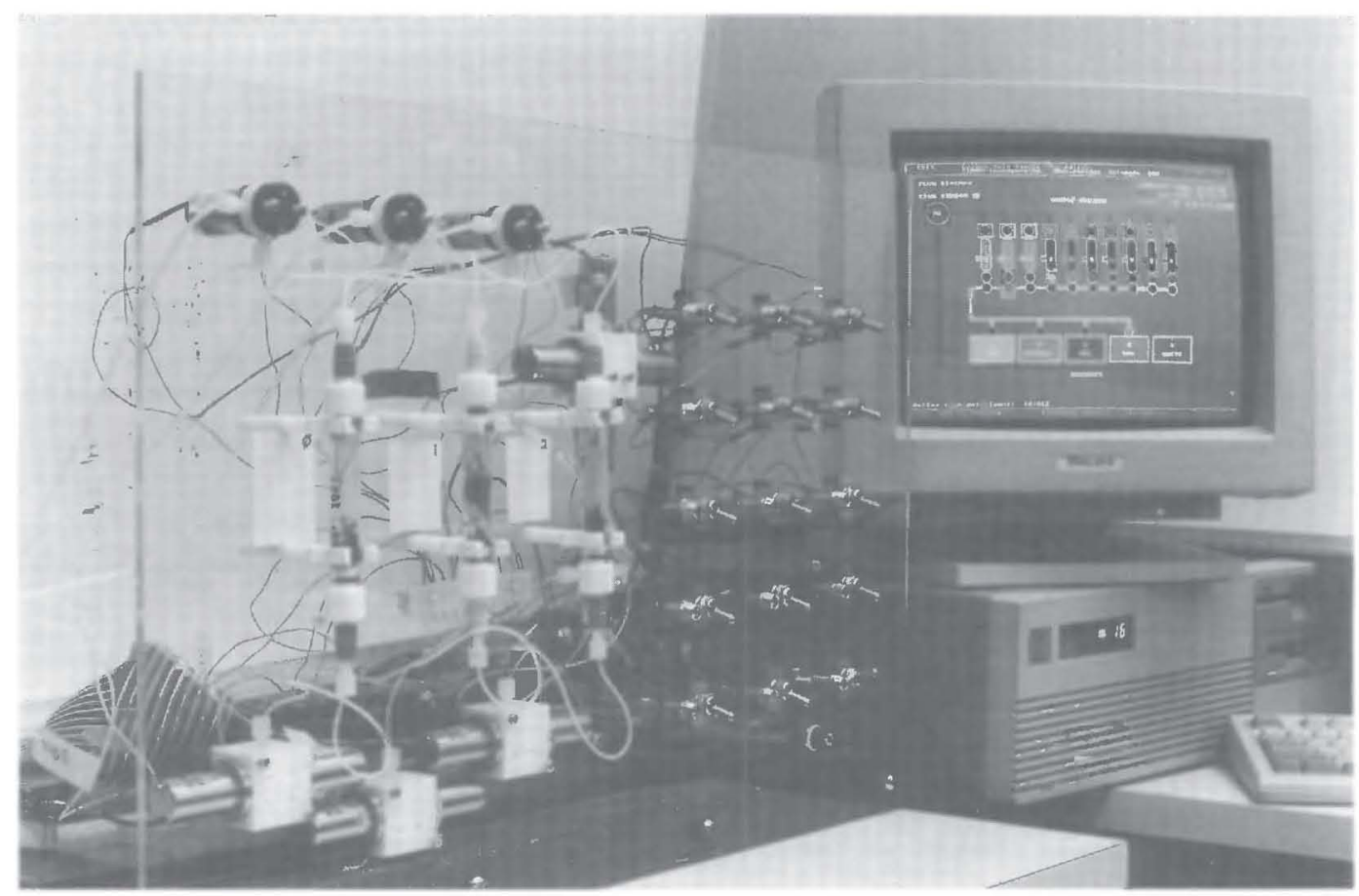

Fig. 1. Computer-automated system for chemically pretreating wood, charcoal and plant fossils for $\mathrm{AMS}{ }^{14} \mathrm{C}$ dating. An IBMcompatible personal computer controls the movement of four solvents over samples contained in the glass columns.

the glass column. Each column drained through Teflon tubing attached to the bottom filter end-cap to a waste receptacle. Our system handles up to four different reagents (Table 2) and processes up to 3 sample columns simultaneously, but it could be modified to run as many as 5-10 samples. Each sample was weighed in the glass column including the filter end-caps and remained in its column throughout the pretreatment process.

We used an IBM-compatible personal computer to control the flow of reagents through the automated pretreatment apparatus. Specially designed computer software activates solenoid switches that control the flow of the reagents for time intervals specified by the program (Table 2). We used the same sequence for all samples except NSRL-750A (Table 1) because the discoloration of the $\mathrm{KOH}$ solution after its third treatment led us to infer that this sample needed additional pretreatment. Because discoloration of the $\mathrm{KOH}$ solution usually signifies contamination with humates, we ran sample NSRL-750A through the entire program sequence again (Table 2).

After drying, the final sample weight was calculated by total yield, and total recoverable yield. The total yield was calculated by subtracting the weight of the sample in the column from the initial weight of the column before pretreatment. The total recoverable yield was the weight of the dried sample after removal from the column. We noted only minor differences in these two values (see below and Fig. 3).

\section{Manual Pretreatment Method}

We pretreated the manual samples in the original sample vials, using the same sequence of reagents used in the automated pretreatment method (Table 2). Reagents were added and removed using 
TABLE 2. Program sequence for one complete sample run with the automated pretreatment system. Our solvent reagents are made from deionized $\mathrm{H}_{2} \mathrm{O}$ and a stock solution of distilled, constant-boiling $\mathrm{HCl}$

\begin{tabular}{|c|c|c|c|c|}
\hline Step & $\begin{array}{l}\text { Sample } \\
\text { Column }\end{array}$ & & Reagent & $\begin{array}{l}\text { Time } \\
\text { (sec) }\end{array}$ \\
\hline 1 & Fill & $\# 1$ & $\mathrm{H}_{2} \mathrm{O}$ pH6.5 & 50 \\
\hline 2 & Fill & \#2 & $\mathrm{H}_{2} \mathrm{O} \mathrm{pH} 3$ & 90 \\
\hline 3 & Purge & & & 30 \\
\hline 4 & Fill & $\# 3$ & $0.5 \mathrm{~N} \mathrm{HCl}$ & 60 \\
\hline 5 & Hold & $\# 3$ & $0.5 \mathrm{~N} \mathrm{HCl}$ & 300 \\
\hline 6 & Purge & & & 30 \\
\hline 7 & Fill & $\# 1$ & $\mathrm{H}_{2} \mathrm{O} \mathrm{pH} 6.5$ & 90 \\
\hline 8 & Purge & & & 30 \\
\hline 9 & Fill & $\# 4$ & $0.5 \% \mathrm{KOH}$ & 60 \\
\hline 10 & Hold & $\# 4$ & $0.5 \% \mathrm{KOH}$ & 600 \\
\hline 11 & Purge & & & 30 \\
\hline 12 & Fill & \#1 & $\mathrm{H}_{2} \mathrm{O}$ pH 6.5 & 120 \\
\hline 13 & Purge & & & 30 \\
\hline 14 & Fill & $\# 2$ & $\mathrm{H}_{2} \mathrm{O}$ pH 3 & 90 \\
\hline 15 & Purge & & & 30 \\
\hline 16 & Fill & \#1 & $\mathrm{H}_{2} \mathrm{O}$ pH 6.5 & 90 \\
\hline 17 & Purge & & & 30 \\
\hline 18 & Fill & $\# 4$ & $0.5 \% \mathrm{KOH}$ & 60 \\
\hline 19 & Hold & $\# 4$ & $0.5 \% \mathrm{KOH}$ & 600 \\
\hline 20 & Purge & & & 30 \\
\hline 21 & Fill & $\# 1$ & $\mathrm{H}_{2} \mathrm{O}$ pH 6.5 & 120 \\
\hline 22 & Purge & & & 30 \\
\hline 23 & Fill & \#2 & $\mathrm{H}_{2} \mathrm{O}$ pH 3 & 90 \\
\hline 24 & Purge & & & 30 \\
\hline 25 & Fill & \#1 & $\mathrm{H}_{2} \mathrm{O} \mathrm{pH} 6.5$ & 90 \\
\hline 26 & Purge & & & 30 \\
\hline 27 & Fill & $\# 4$ & $0.5 \% \mathrm{KOH}$ & 60 \\
\hline 28 & Hold & $\# 4$ & $0.5 \% \mathrm{KOH}$ & 600 \\
\hline 29 & Purge & & & 30 \\
\hline 30 & Fill & $\# 1$ & $\mathrm{H}_{2} \mathrm{O}$ pH 6.5 & 150 \\
\hline 31 & Purge & & & 30 \\
\hline 32 & Fill & $\# 2$ & $\mathrm{H}_{2} \mathrm{O}$ pH 3 & 200 \\
\hline 33 & Purge & & & 120 \\
\hline 34 & End & & & \\
\hline
\end{tabular}

pipettes with the tips modified to $c a .100 \mu$ in diameter to minimize the amount of sample loss. A single pipette was used for each reagent to reduce contamination of the reagents. The time for each step was kept as close as possible to the times of the automated sequence including the time needed to add and remove reagents. After drying, the total yield was calculated by subtracting the initial weight of the sample vial from the final weight.

\section{RESULTS}

Time

All 11 samples processed using the automated system were completed in a total of 4.7 $\mathrm{h}$; processing with the manual method required $15.7 \mathrm{~h}$, or 3.4 times longer than the automated method (Fig. 4). The main reasons for the time savings are: 1) multiple samples can be run simultaneously in the automated method; and 2) adding and draining the reagents takes just a few seconds with the automated system, whereas adding and removing reagents manually using pipettes is very timeconsuming.

\section{Sample Yield}

In 9 of 11 specimens treated, the percent of total yield was higher for the automated system than the manual method. However, after the samples were removed from the glass columns, the total recoverable yield using the automated system was greater only in 6 of 11 specimens (Fig. 3). Apparently, fibrous or minute amounts of sample material were trapped in the frits at the end of the columns and could not be removed. The differences in yield in the automated system ranged from a minimum of $0.5 \%$ for HB561-562A to a maximum of $7 \%$ for NSRL-531A (Fig. 3). For one sample (NSRL-746), the wood completely dissolved during automated pretreatment, whereas the yield during manual pretreatment was $45.54 \%$. The reason for higher manual yield was that the solvents were added very slowly to lessen physical and chemical deterioration of the very friable wood. Although slow, gentle pretreatment yielded wood for dating, it is very possible that contaminants (e.g., humates) could remain. Because no test exists presently to determine when contamination removal is complete and sample dissolution begins, we favor pretreating all samples to completion. If the material disintegrates totally, the sample is labeled "not datable due to dissolution during pretreatment". 


\section{Quality of Pretreatment}

In the first steps of the manual pretreatment process, some samples (especially mosses) float, thus reducing surface contact with the reagents. With the manual method, these buoyant samples were submerged only after special attention from the technician. The automated samples do not suffer

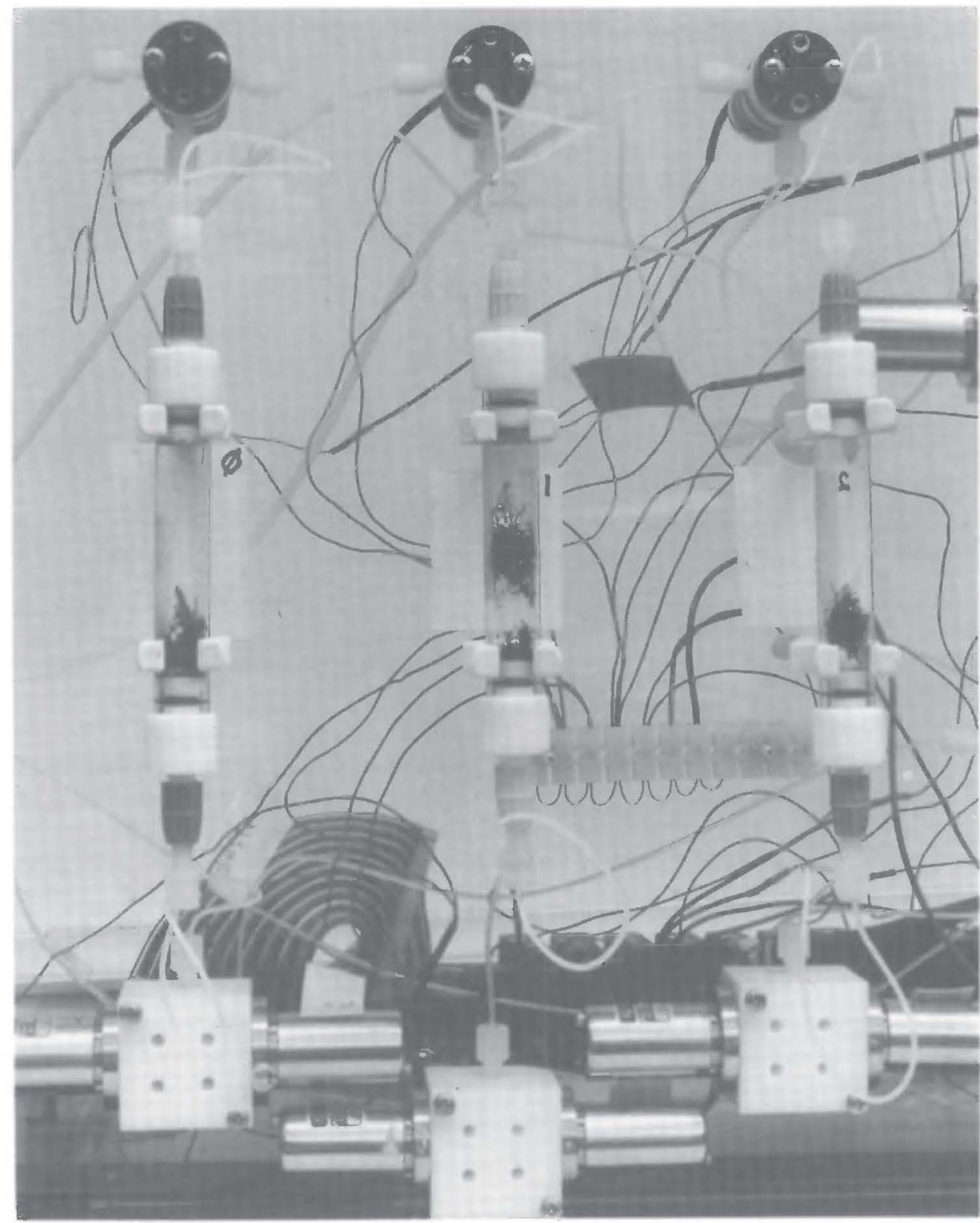

Fig. 2. Close-up of glass columns containing plant macrofossils ready for chemical pretreatment. Solenoid valves control the flow of the reagents upwards into the columns during pretreatment, and purge downward by using nitrogen gas pressure. 


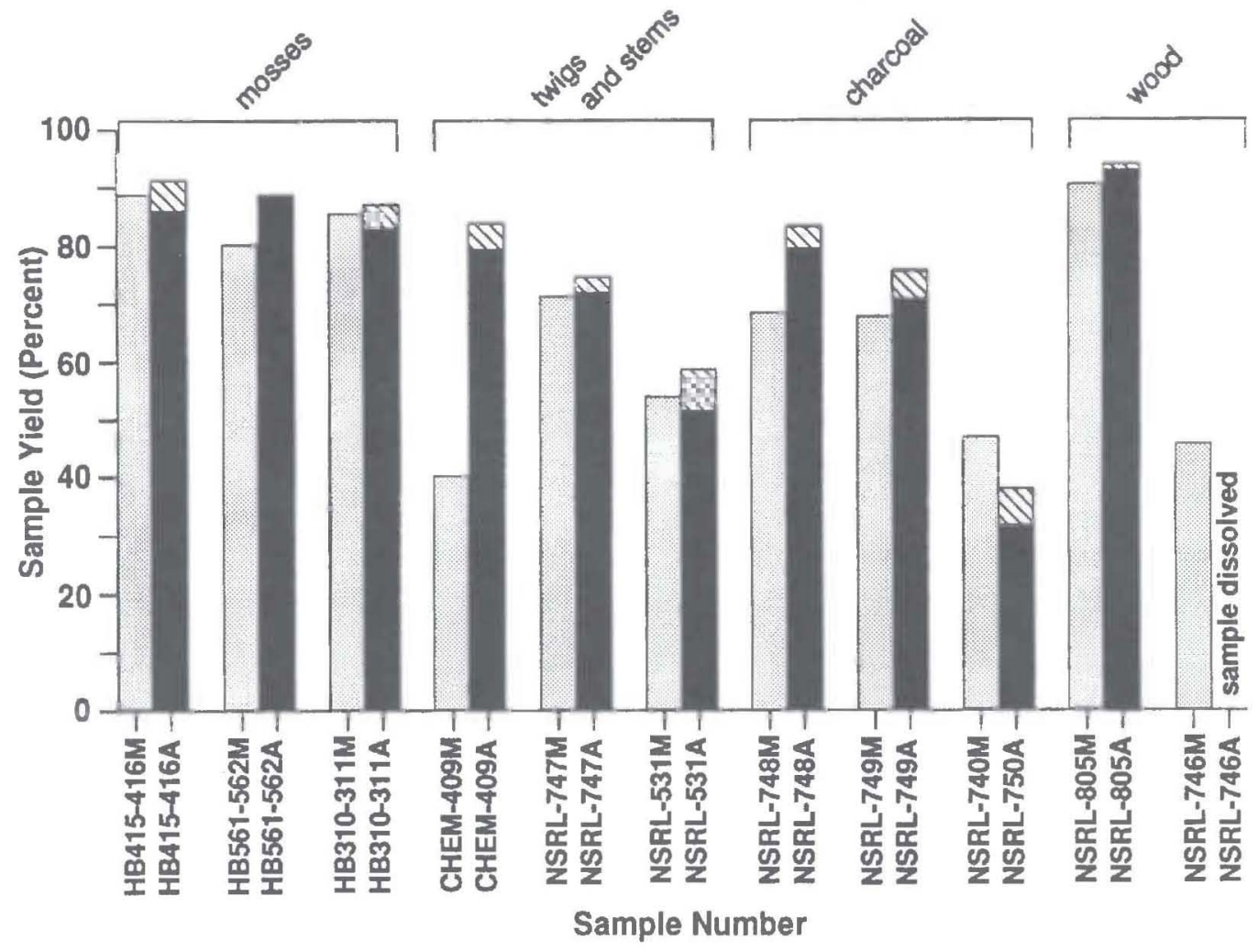

Fig. 3. Sample yields for manual and automated pretreatment methods. W = total yield from manual method; $\square=$ total recoverable yield from automated method; $Q$ = percent of sample not lost during pretreatment but not recoverable from the glass column; $\mathbb{\square}+\square=$ total yield from automated method. Note higher percentage of total yield in automated samples. There was no significant difference between total yield and recoverable yield for most materials.

from this problem because they are sealed in glass columns and thus are completely submerged during the entire pretreatment process. The reagents used with the automated system showed more discoloration than the manually treated samples; in particular, the degree of brown discoloration from humates leached from the sample during the $\mathrm{KOH}$ steps is an indication of the degree of surface contact between the sample and the reagents. Thus, the automated process appears to be more effective in removing humic acid contaminants from the sample. There was also a much greater chance for human error with the manual method. A distracted technician can easily lose track of the sequence and add the wrong reagent. Contamination of the reagents is more likely because the containers are unsealed and pipettes can be inadvertently switched between reagents. With the automated system, the sample is only minimally disturbed because the sample is in contact only with the reagents flowing in and draining from the column.

\section{CONCLUSIONS AND RECOMMENDATIONS}

Because labor costs are a large part of the cost of pretreatment, time savings reduce the cost of pretreatment. The automated method was more than three times faster than the manual method, making the automated method more cost-effective. 


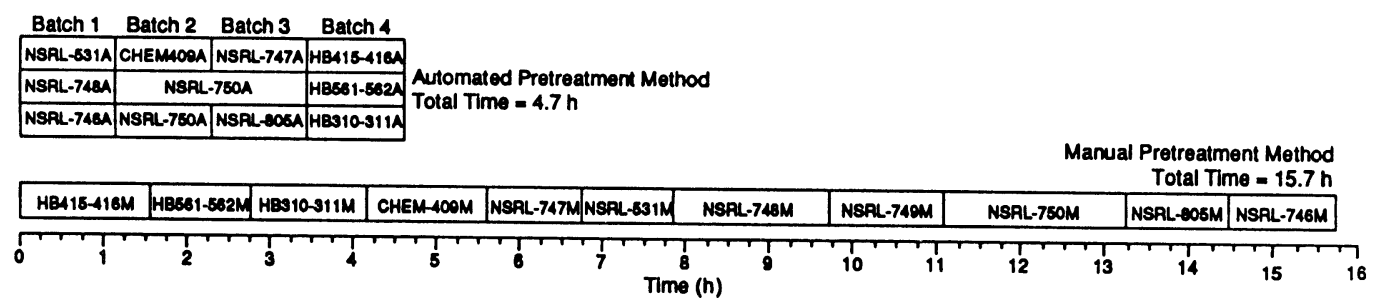

Fig. 4. Cumulative time required to complete pretreatments on 11 specimens using the automated system and the manual method. Using the automated system, three samples were processed simultaneously, permitting all samples to be run in 4 batches. NSRL-750A was run twice because discolored $\mathrm{KOH}$ reagents indicated incomplete pretreatment. The total time to process all 11 samples using the automated system was $4.7 \mathrm{~h}$, compared to $15.7 \mathrm{~h}$ using the manual method.

The total recoverable yield is dependent on the method used and the type of sample material. In most cases, the automated method produced a higher yield, probably because less material is lost draining the reagents through filters than by siphoning off reagents manually. Extremely fragile materials that require special care, such as very soft wood or fine-grained charcoal, showed a higher yield by manual pretreatment. For most materials (plants, mosses, twigs and stems, most charcoal and fibrous wood) the yield is higher using the automated method. A necessary modification would be to use finer porosity frits in the filter end-caps. Smaller pore sizes would be smoother and occlude less of the fibrous sample. The second modification would be to decrease the gas pressure that moves the solutions in and out of the system. By decreasing the flow rate, the automated system would more closely mimic the manual pretreatment of delicate samples.

The darker discoloration of the $\mathrm{KOH}$ solutions we observed during the automated pretreatments indicates that this method is more thorough in removing humates from the specimens. Although there was no statistically significant difference in the paired ${ }^{14} \mathrm{C}$ ages, 6 out of 7 pairs of samples gave older ages for the automated samples, thus supporting our observation that the automated pretreatment process was slightly better (Table 1).

The next generation instrument is under development and will provide more control over pretreatment conditions. The improvements will include: 1 ) ability to vary linearly the $\mathrm{KOH}$ concentrations from $0.01 \%$ to $0.5 \%$; 2) change flow rates to accommodate friable samples, 3 ) provisions for treating samples from room temperature to $80^{\circ} \mathrm{C} ; 4$ ) improvement of software to enable rerunning of specific, severely contaminated samples; and 5) rewriting the software for Macintosh systems.

\section{ACKNOWLEDGMENTS}

Our research is supported by the National Earthquake Hazards Reduction Program and the Global Change and Climate History Program of the U.S. Geological Survey, the U.S. Nuclear Regulatory Commission and National Science Foundation Grants EAR 90-18678, EAR 90-18958 and EAR 9118683. We thank Glenn Fryer, CIMAX, Inc., Breckenridge, Colorado, for his assistance in programming the DOS software to control the instrumentation.

\section{REFERENCE}

Gagnon, A. R. and Jones, C. A. 1993 AMS-graphite target production methods at the Woods Hole Oceano- graphic Institution during 1989-1991. Radiocarbon 35 (2): 301-310. 